\title{
MACAGNO, Lorenzo. 2006. Outros Muçulmanos. Islão e narrativas coloniais. Lisboa: Imprensa de Ciências Sociais/Instituto de Ciências Sociais da Universidade de Lisboa. 254 pp.
}

Silvia Montenegro (CONICET/UNR)
Outros Muçulmanos é um desses bons trabalhos antropológicos, escassos em nossos dias. Antes de mais, este livro nos apresenta um forte diálogo com a tradição antropológica, implícito na exploração das potencialidades do método etnográfico, nas formas que assume o uso da história e a interrogação das fontes. Nele encontramos uma valorização das categorias nativas e do saber local que, no entanto, não sacraliza o ponto de vista nativo, mas o conecta às macrodimensões que, através do tempo, marcaram as narrativas globais sobre Moçambique, desde o período colonial aos nossos dias. Narrativas nas quais também se apoiariam as distintas políticas de interpretação da antiga presença do Islã neste país.

Trata-se de um conjunto de oito capítulos que podem ser lidos autonomamente, pois todos eles abordam um problema delimitado, cujas redes de significado o leitor vai tecendo ao longo da totalidade do livro. O trabalho de campo, é importante ressaltar, constrói-se a partir de diferentes estadas no campo, a primeira em 1996, depois em 1998, 2000 e 2003. Esse esforço é traduzido numa apresentação dinâmica do Moçambique contemporâneo, que se inicia em uma etapa de profunda revisão do passado ao término de uma das mais prolongadas guerras civis da África. Um momento permeado pela esperança de construção de um novo país sobre as feridas dos cruéis processos históricos que o marcaram. A pesquisa também se alimenta da análise de importantes fontes documentais, como as consultadas no Arquivo Nacional da Torre do Tombo, em Lisboa. Relevantes são as perguntas que o autor dirige aos documentos. Através de uma interpelação desprovida de ingenuidade, estes passam a interagir com o presente e com uma trama de significados que, concomitantemente os transcende e os integra à multiplicidade de narrativas das quais fora e é objeto Moçambique. A isto é acrescentado um valioso conjunto de entrevistas, principalmente as realizadas em Lisboa, com alguns protagonistas centrais da política colonial portuguesa, dentre eles, aqueles que produziram as interpretações oficiais sobre o Islã no contexto colonial.

Os capítulos 1 e 2 permitem que conheçamos a complexa e dinâmica 
do imaginário lusotropical. É neste último discurso que o autor resgata, em novos termos, a influência cultural dos "mouros", o que lhe permite indagar sobre o dinâmico lugar ocupado pelos muçulmanos no imaginário colonial. Em "Narrativas Jurídico-Coloniais" (capítulo 1), é analisada a construção jurídica do indígena e de sua categoria oposta: o assimilado. O papel e as posições de Antonio Enes são fundamentais nesta parte do livro, bem como as discussões de caráter jurídico, político e administrativo que conformaram a moderna política colonial portuguesa, a partir do final do século XIX. Como especifica o autor, neste período, a construção das taxonomias ainda não se apoiava em especialistas como etnógrafos, antropólogos ou sociólogos; entretanto, aquela geração já clamava a necessidade de codificar os usos e costumes dos nativos com vistas à aplicação de leis de acordo com o "grau de civilização". É importante ressaltar que a política colonial não é assumida pelo autor como se configurasse uma totalidade homogênea; a explicitação de suas distintas tonalidades permite a abordagem de continuidades e descontinuidades originadas por novos elementos discursivos e legislativos, do aprofundamento de alguns dilemas e da busca de soluções a certas tensões próprias do aparato colonial em seu conjunto. Assim, entre a geração de Enes e o advento do Estado Novo e a ditadura salazarista em Portugal, o assimilacionismo gradual segue sendo parte do projeto, mesmo que, nesta última etapa, o nacionalismo cultural e econômico, vinculado à idéia de Império, tenha agregado ao ideal do assimilacionismo jurídico o pressuposto de um assimilacionismo espiritual. É central neste momento a explicação do autor sobre o assimilacionismo descentralizador, enquanto uma forma de postergar, em nome da tutela, a outorga de direitos políticos. É durante o Estado Novo e, mais precisamente, com a publicação, em 1946, do Projeto Definitivo do Direito Privado dos Indígenas, no qual são codificados os usos e costumes, que se situa o ponto de inflexão para a posterior compreensão dos vínculos entre administração colonial e comunidades mulçumanas. Neste período, o autor assinala a correspondência lógica entre o projeto de assimilação evolutiva e o de assimilação legal e o surgimento de uma nova categoria intermediária entre indígenas e assimilados: os evoluídos. A partir da atuação de Marcello Caetano e a cristalização da idéia de assimilação espiritual, entendida como a incorporação gradual dos valores portugueses, torna-se mais explícita para o autor a ambigüidade crescente da narrativa assimilacionista. $O$ fim do Indigenato, em virtude da abolição do Estatuto dos Indígenas, conduz-nos à análise do papel intelectual de Adriano Moreira, figura importante da política colonial salazarista. No entanto, como demonstra o autor, a categoria indígena, agora substituída pela de autóctones, pouco transformaria a realidade das populações assim classificadas. Pode-se dizer que, na sua totalidade, este capítulo apresenta a construção de uma matriz discursiva basicamente jurídica que, instrumentalizada mediante regras, estatuto e leis, consegue criar o indígena, outorgando-Ihe, em tal processo de nominação, uma existência real.

Em "O Lugar dos Muçulmanos no Luso-Tropicalismo" (capítulo 2), encontramos uma abordagem original da ideologia lustropicalista. Por um lado, porque mostra como a narrativa colonial nela encontra um novo ar de plasticidade; por outro, porque o orientalismo é analisado subjacentemente à arabofilia de Gilberto Freyre. $O$ autor assinala a integração tardia do lusotropicalismo ao conjunto do imaginário colonial, assumindo, a partir do fim do Indigenato, a forma de uma autêntica "vulgata colonial". É nessa elaboração de uma etnogenealogia para a civilização lusotropical que a antiga presença muçulmana será recuperada. Hibridismo, miscigenação, plasticidade, doce tratamento aos escravos, pouca importância da raça e herança assimilacionista do caráter 
português passariam a ser considerados como derivados do legado árabo-islâmico. Indubitavelmente, o legado orientalista e, eventualmente, romântico do lusotropicalismo é um tema pouco explorado, como também Lorenzo Macagno sugere, para o caso do Brasil.

Nos capítulos subseqüentes, o autor centra sua análise, especificamente, na presença do Islã em Moçambique e acertadamente o faz traçando um panorama histórico dessa presença, que persiste através dos séculos. "Os Muçulmanos no Imaginário Colonial” (capítulo 3) permite-nos compreender que a presença do Islã, a partir de meados do século XIX, na costa oriental africana é fruto de uma ampla rede do que hoje chamaríamos fluxos de significados, não somente em termos religiosos, mas políticos e culturais. Esses fluxos, dos quais se nutriram as confrarias sufis do norte de Moçambique, sustentaram-se, em alguns casos, nas rotas comerciais que desde Zanzibar chegavam a esta região, mas que também se irradiavam de algumas ilhas do Oceano Índico. Neste sentido, a rede aparece como um diálogo intracolonial que conectava três áreas, na altura sob o mandato de distintas potências coloniais: Zanzibar, sob o domínio britânico, as Ilhas Comores e Madagascar, sob o domínio francês. O autor consegue demonstrar não somente a persistência da presença do Islã, mas também do exercício, por parte da administração colonial, de observá-lo. Desde os primeiros momentos da ocupação efetiva, a presença muçulmana era percebida no norte, seja para mostrar a difícil tarefa de conversão, seja para advertir o quanto ela dificultaria a empresa colonial ou para assinalar, até a década de 1950, sua suposta ênfase desnacionalizadora. Neste capítulo, encontramos uma análise de como a imaginação colonial se torna ativa frente ao desafio do Islã, vislumbrando-o como inimigo a ser conquistado ou reclamado e, inclusive, em alguns casos, aproveitando de suas cisões internas para produzir seu enfraquecimento. Neste ponto aparecem as diferentes tentativas de domesticação desta Outridade esquiva, com a qual o colonialismo experimentou distintas táticas, mas que deveu antes conhecer, ainda que de modo imperfeito e através da produção de um saber etnocêntrico. Lorenzo Macagno nos transmite essa espécie de sofreguidão que guiava as tentativas de cooptação e de utilização das confrarias, sobretudo na campanha de ação psicológica da qual foram objeto para, já nas vésperas da luta armada, colocá-las a favor da luta contra a "guerra subversiva". A criação do Grupo de Trabalhos sobre Assuntos Islâmicos plasmaria essa ação e deixaria pegadas que podem ser rastreadas no presente para a compreensão da diversidade do Islã e das suas disputas internas, tenuemente ancoradas num ajuste de contas com esse passado. Novamente encontramos a figura dos intelectuais a mando desta empresa, fato que nos recorda que todo colonialismo não é mera ocupação efetiva mediante a força militar, mas que se alimenta da criação de complexas e ambíguas cosmologias sobre o Outro, as quais servem de fundamento cultural à intervenção. A atuação de Fernando Amaro Monteiro ocupa um lugar destacado na ideação de um conjunto de ações de sedução, que vão desde o financiamento de viagens a Meca até a restauração de mesquitas. Ao focalizar alguns dos acontecimentos que têm lugar a partir de 1970, o autor explora uma das raízes das dissonâncias entre as vertentes mulçumanas. O suposto irrompimento do wahabismo de inspiração saudita é parte desse processo, concomitantemente ao debilitamento das confrarias, suspeitas por seus vínculos com o colonialismo, e ao ascenso de organizações como o Conselho Is/âmico de Moçambique. Islã "puro" em tensão com o Islã texturizado pela cultura local, o que Ernest Gellner definiu como o auge do "alto Islã" letrado, estrito, elitista e universalista, acima do "baixo Islã" oral, poroso, carismático e localmente arraigado. Partindo do reconhecimento do qual parte toda a moderna 
antropologia sobre o Islã, o autor sabe perfeitamente que não se trata de uma religião homogênea, que suas expressões locais indigenizadas supõem interpretações particulares, num diálogo de oposição e associação com outras interpretações. Por este motivo, e sem temer esta multiplicidade aparentemente caótica, é nas "vielas labirínticas dos subúrbios do caniço de Nampula" que o autor vai ao encontro desse Islã vivido e dos saberes locais que ali o sustentam. Assim, os dois capítulos seguintes: "Islão e Saber Local" (capítulo 4) e "Maulide, os Dervixes da llha" (capítulo 5) constituem o coração etnográfico deste livro. Lidos em conjunto, implicam-se mutuamente, pois são outras vozes as que neles nos falam. Através do primeiro, percorremos as mesquitas de Nampula, acompanhados por Momade, essa espécie de etnógrafo espontâneo que entra em sintonia com o autor e que revela seu conhecimento fragmentado, seus valiosos kitabs, permitindo descobrir o uso dos talismãs, sendo ele próprio uma espécie de médico tradicional. Neste capítulo, enfatizam-se as conseqüências da circulação e da escritura árabe e as mediações com a cultura oral. Os livros de Momade possibilitam tanto a reconstrução das circulações culturais tecidas pelo Islã através do Oceano Índico, como as tensões com as quais se enfrenta esse Islã popular, pouco ortodoxo e híbrido aos olhos do "ascendente" wahabismo. E o que é mais importante, este capítulo explicita os limites do assimilacionismo colonial que pretendeu fazer tabula rasa ao passar por alto do profundo e eclético alicerce que esses saberes haviam construído. O segundo capítulo etnográfico nos conduz à llha de Moçambique e parte de uma interessante proposta: através do conhecimento das práticas rituais da minoria de uma minoria, podemos melhor conhecer - e por contraste - o tipo de Islã professado por aqueles que os vislumbram como "clandestinos". Os Homens do Maulide representam a remanescência de uma confraria e realizam um ritual comemorativo, cujo mais notável diacrítico é o uso de estiletes metálicos que são cravados nos corpos em transe. O autor se perguntará sobre as práticas deste Islã "espontâneo, quase físico", sem desconsiderar que seus praticantes fazem parte do grupo mais miserável da ilha e mais subalterno em relação às lideranças religiosas. É curioso que a mesma cerimônia tenha sido observada, como revela o autor, há mais de um século pelo próprio Enes, em cujas crônicas envidencia-se a repugnância que o ritual lhe suscitava: "parem, selvagens!". "Basta, canibais." Este capítulo nos mostra, em seu conjunto, a riqueza do caleidoscópio mulçumano e a persistência de práticas localizadas às margens do Islã mais escriturista.

Os três capítulos finais ressaltam momentos fundamentais do diálogo interno entre as comunidades muçulmanas (capítulo sexto) e entre estas e os porta-vozes do aparato estatal (sétimo e oitavo capítulos). "A Recomposição das Lideranças Muçulmanas" (capítulo 6) põe em xeque a idéia da conspiração ou invasão wahabita em Moçambique como ponto nevrálgico da compreensão da diversidade do Islã. Um maniqueísmo expressado na oposição wahabismo versus confrarias, que a própria etnografia parece derrubar, deslocando a análise do irrompimento exógeno ao plano do tratamento dos elementos endógenos que criaram o terreno para a chegada dos "reformadores". Através deste capítulo, ressalta-se que o temor à conspiração wahabita surge no período tardo-colonial e que a superestimação das influências desta corrente pode ser um obstáculo à compreensão da composição e recomposição das lideranças muçulmanas em Moçambique. A chave da análise parece melhor situada neste plano endógeno, nas disputas internas das confrarias, no surgimento de novos intelectuais e nas tensões entre uma inspiração carismática e uma inspiração mais mediada pelo conhecimento dos ulemas, tensões sobre as quais posteriormente atuariam, de fato, as forças exógenas. Mais chaves para essa análise são encontradas nos dois últimos capítulos. Em "Yussuf Arab: ambigüidades da luta anticolonial" (capítulo 7), torna-se evidente 
que a posição dos muçulmanos na luta pela independência não foi homogênea. A análise da tortuosa trajetória de Yussuf Arab nos mostra a multiplicidade de causas que impediram o reconhecimento de uma posição geral das comunidades islâmicas. Os encontros entre Yussuf e Eduardo Mondlane, cuidadosamente reconstruídos através das fontes, explicitam sua proximidade com a FRELIMO, mas também a desconfiança - e, por que não? - as desventuras dessa relação. É que a luta pela independência também foi impactante para as comunidades islâmicas, pressupôs novos desafios ao seu posicionamento e, como ressalta o autor, "novos porta-vozes entraram em cena". É assim que no último capítulo, "Samora Machel e os Muçulmanos", as relações entre a direção da FRELIMO e os muçulmanos são analisadas através de dois momentos: o da independência, marcado por uma certa hostilidade doutrinária em relação às organizações religiosas em geral, e o segundo momento, cujo fato principal é a reunião de 1982, na qual Samora Machel busca afinidades e compatibilidades recíprocas com os líderes religiosos. No primeiro período dessas relações, a ideologia da construção do Homem Novo é central para a compreensão das tensões. O autor trabalha com um incidente-metáfora e reconstrói etnograficamente o leque de possíveis leituras, entre os muçulmanos, da história em questão: Samora Machel teria entrado na mesquita sem se descalçar, o que suscita um conjunto de narrativas que podem agrupar-se em diversas posições. O segundo conjunto de narrativas se vincula à reunião de $1982 \mathrm{com}$ as comunidades religiosas, a partir da qual são analisadas as possíveis compatibilidades, bem como o pêndulo das alianças, cujo oscilar se relacionava ao pertencimento étnico e religioso dos distintos grupos e já se vinculava ao surgimento de novos porta-vozes de algumas organizações islâmicas. Cabe tecer algumas conclusões acerca da leitura deste livro, para quem desejar abordar uma compreensão de Moçambique entrando pela porta do Islã, mas, ao mesmo tempo, fundamentais para compreender o Islã entrando pela especificidade da história de Moçambique. O trabalho, alicerçado em uma rigorosa, cuidadosa e documentada investigação, recorda-nos que os mundos locais se formam em diálogo com as difusas lealdades transnacionais, que as mudanças são tributárias das permanências e que todos esses elementos imbricam-se na compreensão atual das relações entre o Islã e a esfera pública e entre o Islã e os mundos comunais. Longe dos discursos monolíticos e essencialistas, Outros Muçulmanos assume a pluralidade do Islã, não como um problema do qual tanto fugiam os orientalistas, mas como uma realidade etnográfica, cuja abordagem somente se faz possível pelo respeito a essa complexidade de formas que o constituem e a essa multiplicidade de olhares que ele suscita.

Tradução para o português de Angela Lazagna.

Sílvia Montenegro é doutora em Sociologia pelo PPGAS/IFCS da Universidade Federal do Rio de Janeiro, pesquisadora do Consejo Nacional de Investigaciones Científicas y Técnicas (CONICET) e professora do Departamento de Antropologia da Universidad Nacional de Rosario (Argentina). 
200 